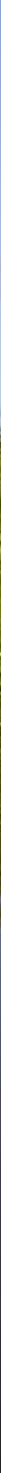

\title{
Watergebruik in de land- en tuinbouw, 2015 en 2016
}





\section{Watergebruik in de land- en tuinbouw, 2015 en 2016}

R.W. van der Meer 
R.W van der Meer, 2018. Watergebruik in de land- en tuinbouw, 2015 en 2016. Wageningen, Wageningen Economic Research, Nota 2018-105. 20 blz.; 1 fig.; 5 tab.; 6 ref.

Deze notitie beschrijft hoe het watergebruik in de land- en tuinbouw, uitgesplitst naar

7 stroomgebieden, wordt berekend. De resultaten van de berekeningen dienen als input voor de CBSpublicaties Milieurekeningen, Groene Groei en het Compendium voor de Leefomgeving. De basis van de berekeningen wordt gevormd door de resultaten van de bedrijven uit het Bedrijveninformatienet van Wageningen Economic Research. Voor het aggregeren van de bedrijfsresultaten naar sectoren en stroomgebieden wordt gebruikgemaakt van statistical matching.

Trefwoorden: watergebruik, land- en tuinbouw, bedrijveninformatienet, statistical matching

Dit rapport is gratis te downloaden op https://doi.org/10.18174/463716 of op www.wur.nl/economicresearch (onder Wageningen Economic Research publicaties).

(C) 2018 Wageningen Economic Research

Postbus 29703, 2502 LS Den Haag, T 07033583 30, E communications.ssg@wur.nl, www.wur.nl/economic-research. Wageningen Economic Research is onderdeel van Wageningen University \& Research.

\section{(cc) BY-NC}

Wageningen Economic Research hanteert voor haar rapporten een Creative Commons Naamsvermelding 3.0 Nederland licentie.

(C) Wageningen Economic Research, onderdeel van Stichting Wageningen Research, 2018

De gebruiker mag het werk kopiëren, verspreiden en doorgeven en afgeleide werken maken. Materiaal van derden waarvan in het werk gebruik is gemaakt en waarop intellectuele eigendomsrechten berusten, mogen niet zonder voorafgaande toestemming van derden gebruikt worden. De gebruiker dient bij het werk de door de maker of de licentiegever aangegeven naam te vermelden, maar niet zodanig dat de indruk gewekt wordt dat zij daarmee instemmen met het werk van de gebruiker of het gebruik van het werk. De gebruiker mag het werk niet voor commerciële doeleinden gebruiken.

Wageningen Economic Research aanvaardt geen aansprakelijkheid voor eventuele schade voortvloeiend uit het gebruik van de resultaten van dit onderzoek of de toepassing van de adviezen.

Wageningen Economic Research is ISO 9001:2008 gecertificeerd.

Wageningen Economic Research Nota 2018-105 | Projectcode 2282200420

Foto omslag: Shutterstock 


\section{Inhoud}

Samenvatting 5

S.1 Belangrijkste uitkomsten $\quad 5$

1

Inleiding $\quad 6$

1.1 Aanleiding $\quad 6$

$\begin{array}{lll}1.2 & \text { Doel } & 6\end{array}$

$\begin{array}{lll}1.3 & \text { Leeswijzer } & 6\end{array}$

2 Methodiek $\quad 7$

$\begin{array}{lll}2.1 & \text { Inleiding } & 7\end{array}$

$\begin{array}{lll}2.2 & \text { Bedrijfstypen en stroomgebieden } & 7\end{array}$

$\begin{array}{lll}2.3 & \text { Statistical matching } & 8\end{array}$

2.4 Bijschatting 9

2.5 Drenking vee $\quad 9$

$\begin{array}{lr}3 & \text { Uitkomsten } \\ \end{array}$

$\begin{array}{lll}3.1 & \text { Inleiding } & 10\end{array}$

$\begin{array}{ll}3.2 \text { Watergebruik land- en tuinbouw } & 10\end{array}$

3.2.1 Totaal watergebruik 10

3.2.2 Watergebruik per bedrijf 11

$\begin{array}{lll}3.3 & \text { Beregend areaal } & 11\end{array}$

3.4 Resultaten in het kort $\quad 12$

$\begin{array}{ll}\text { Literatuur en websites } & 13\end{array}$

$\begin{array}{lll}\text { Bijlage } 1 \text { Watergebruik vanaf } 2001 & 14\end{array}$

Bijlage 2 Watergebruik naar sector en stroomgebied 15

$\begin{array}{lll}\text { Bijlage } 3 & \text { Watergebruik per bedrijf } & 18\end{array}$

$\begin{array}{llr}\text { Bijlage } 4 & \text { Statistical matching } & 19\end{array}$ 



\section{Samenvatting}

\section{S.1 Belangrijkste uitkomsten}

Deze notitie beschrijft hoe het watergebruik in de land- en tuinbouw, uitgesplitst naar 7 stroomgebieden, wordt berekend. De resultaten van de berekeningen dienen als input voor de CBSpublicaties Milieurekeningen, Groene Groei en het Compendium voor de Leefomgeving. De basis van de berekeningen wordt gevormd door de resultaten van de bedrijven uit het Bedrijveninformatienet van Wageningen Economic Research. Voor het aggregeren van de bedrijfsresultaten naar sectoren en stroomgebieden wordt gebruik gemaakt van statistical matching.

Enkele uitkomsten:

- In 2015 is er aanzienlijk meer beregend dan in 2016 als gevolg van een droge periode van april tot en met juni. Mede hierdoor is het watergebruik in 2015148 miljoen $\mathrm{m}^{3}$. In 2016 daalde dit tot 120 miljoen $\mathrm{m}^{3}$.

- Het leidingwatergebruik per bedrijf stijgt, mede door de toegenomen omvang van de bedrijven. In 2016 werd er gemiddeld bijna $800 \mathrm{~m}^{3}$ leidingwater gebruikt.

- Water voor het drenken van vee en beregening maken een groot deel uit van het totale watergebruik in de agrarische sector. 


\section{$1 \quad$ Inleiding}

\section{$1.1 \quad$ Aanleiding}

In de land- en tuinbouw wordt leidingwater gebruikt bijvoorbeeld voor het drenken van vee of voor het reinigen van stallen. Ook wordt er oppervlakte- en grondwater gebruikt voor bijvoorbeeld het beregenen van gewassen. Vooral de mate waarin oppervlakte- en grondwater wordt gebruikt, wordt bepaald door de weersomstandigheden. In droge jaren wordt er immers meer beregend dan in de natte jaren.

Ten behoeve van de CBS-publicaties Milieurekeningen, Groene Groei en het Compendium voor de Leefomgeving levert Wageningen Economic Research cijfers aan het CBS met betrekking tot het watergebruik in de agrarische sector. Deze nota is een actualisatie van de nota Watergebruik in de agrarische sector 2013 en 2014 (Van der Meer, 2016).

\subsection{Doel}

Het doel is het vaststellen van het watergebruik in 2015 en 2016 van 5 land- en tuinbouwsectoren in 7 stroomgebieden in Nederland (zie paragraaf 2.2). Hierbij worden onderstaande typen water onderscheiden:

- leidingwater (drenking en overig)

- gietwater

- grondwater voor irrigatie

- oppervlaktewater voor irrigatie

- grond-/oppervlaktewater voor drenking.

Het watergebruik wordt bepaald voor de sector als geheel. Ook wordt het gemiddelde gebruik per bedrijf berekend. Daarnaast wordt het beregende areaal gerapporteerd.

\subsection{Leeswijzer}

In deze nota wordt beschreven hoe de berekeningen van Wageningen Economic Research hebben plaatsgevonden (hoofdstuk 2). De uitkomsten van de berekeningen (hoofdstuk 3) zijn de basis voor verdere verwerking door het CBS, en worden niet nader toegelicht in deze nota. Deze nota dient gezien te worden als een achtergronddocument ten behoeve van de opdrachtgever. De rapportage heeft betrekking op de jaren 2015 en 2016. Voor voorgaande jaren zijn eerdere rapportages verschenen (zie literatuurlijst). 


\section{$2 \quad$ Methodiek}

\section{$2.1 \quad$ Inleiding}

Dit hoofdstuk beschrijft de gehanteerde methode en uitgangspunten voor het bepalen van het watergebruik van de totale land- en tuinbouwsector. De berekening van het watergebruik vindt plaats op basis van de resultaten van de steekproefbedrijven in het Bedrijveninformatienet van Wageningen Economic Research. Door de uitkomsten van de steekproefbedrijven te wegen kan een schatting worden gemaakt van het watergebruik van de totale steekproefpopulatie. De wegingsfactoren worden met behulp van statistical matching bepaald. De matchingprocedure is aangepast ten opzichte van voorgaande jaren (zie paragraaf 2.3). Ook wordt een bijschatting gemaakt, omdat het CBS het watergebruik wil weten van de totale agrarische sector, dus ook van de bedrijven die buiten het steekproefkader van Wageningen Economic Research vallen en daardoor niet gerepresenteerd worden in de steekproef (zie paragraaf 2.4).

\subsection{Bedrijfstypen en stroomgebieden}

Het watergebruik wordt voor 5 landbouwsectoren bepaald:

- akkerbouw

- fruitteelt

- tuinbouw (opengrondstuinbouw en glastuinbouw exclusief fruitteelt)

- veehouderij

- overige landbouw.

De stroomgebieden die in de rapportage worden onderscheiden zijn afgebeeld in figuur 2.1

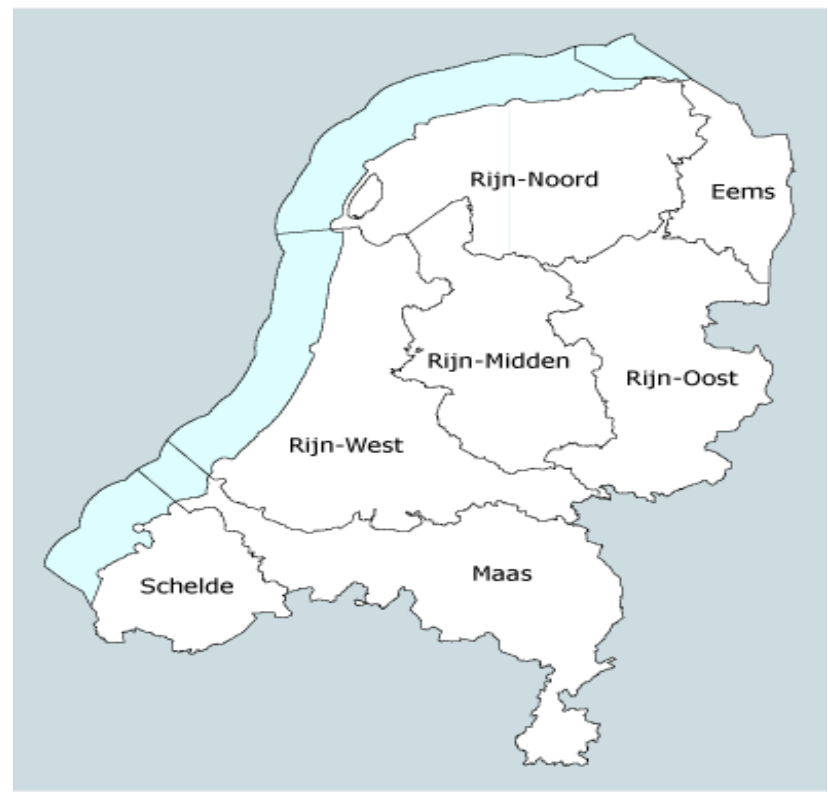

Figuur 2.1 Stroomgebieden van Nederland 


\subsection{Statistical matching}

Het CBS wil een uitsplitsing van het watergebruik naar de verschillende agrarische sectoren en naar de diverse stroomgebieden. Hierbij is het gewenst om rekening te houden met de structuur en de productieomstandigheden van de bedrijven in de afzonderlijke stroomgebieden. De basis van deze analyse zijn de bedrijven uit het Bedrijveninformatienet van Wageningen Economic Research (zie voor meer achtergrondinformatie over de samenstelling van de steekproef het rapport van Ge et al., 2018). De steekproef is een disproportionele steekproef waardoor insluitingskansen voor bedrijven binnen een sector niet gelijk zijn. Hier wordt rekening mee gehouden door gewichten toe te kennen aan de bedrijven. Vervolgens kunnen de resultaten van de steekproefbedrijven worden opgeschaald naar de totale steekproefpopulatie met behulp van deze wegingsfactoren. De standaardwegingsfactoren in het Bedrijveninformatienet houden geen rekening met het stroomgebied waarin het bedrijf gevestigd is. Dit kan ertoe leiden dat als de standaardwegingsfactoren worden gebruikt, de gemiddelde bedrijfsstructuur van de steekproefbedrijven afwijkt van de daadwerkelijke gemiddelde structuur van de bedrijven in het stroomgebied. Met behulp van statistical matching worden wegingsfactoren bepaald die wel rekening houden met de regio waarin het bedrijf gevestigd is (zie bijlage 4 voor de achtergronden). Bij statistical matching worden steekproefbedrijven (Bedrijveninformatienet) gekoppeld aan bedrijven uit de steekproefpopulatie (Landbouwtelling). De koppeling vindt plaats op basis van kenmerken die zowel in de Landbouwtelling als in het Bedrijveninformatienet worden vastgelegd. De kenmerken waarop gekoppeld wordt, worden de matchingvariabelen genoemd. De mate van overeenkomst tussen de gekoppelde bedrijven, bepaalt de hoogte van de wegingsfactor. Er zijn zes kenmerken gebruikt voor de matching; tabel 2.1 geeft de gehanteerde matchingvariabelen.

Tabel 2.1 Kenmerken warop statistical matching plaatsvindt

\begin{tabular}{ll} 
Exact te matchen: & Best passend \\
\hline Jaar & X- en Y-coördinaten van het bedrijf \\
\hline Bedrijfstype & Grondsoort \\
\hline & Aantal ha \\
\hline & Bedrijfsomvang in Standaard Output \\
\hline
\end{tabular}

Voor matching tussen steekproefbedrijven en bedrijven uit de populatie komen alleen bedrijven in aanmerking uit hetzelfde jaar en die van hetzelfde bedrijfstype zijn. Uit deze 'pools' worden vervolgens de 3 bedrijven geselecteerd met een zo gelijk mogelijk areaal (ha), grondsoort en economische omvang gemeten in euro Standaardopbrengst (SO). Het bedrijf dat hemelsbreed (op basis van $\mathrm{X}$ - en $\mathrm{Y}$-coördinaten) het dichtst bij het te matchen bedrijf ligt, krijgt daarbij een hogere weging dan bedrijven die op grotere afstand liggen. Er is gekozen voor deze matchingvariabelen, omdat het watergebruik afhankelijk is van zowel de omvang van het bedrijf als de intensiteit van de productie. Omdat neerslag sterk lokaal kan verschillen, speelt ook de locatie van het bedrijf een belangrijke rol bij de matching. Dit geldt vooral voor de bedrijven die beregenen. Het kan daarom voorkomen dat een bedrijf gematcht wordt aan een bedrijf met dezelfde grondsoort uit een ander stroomgebied. Aangenomen is dat dit een betere voorspeller is voor het watergebruik dan een match met een bedrijf dat weliswaar in hetzelfde stroomgebied ligt maar wel tientallen kilometers verderop.

Voor het landbouwtellingsbedrijf wordt het watergebruik geschat op basis van de gematchte bedrijven uit het Informatienet. Van de bedrijven uit het Informatienet wordt het watergebruik per SO bepaald. Het watergebruik van het landbouwtellingsbedrijf wordt benaderd door het watergebruik per SO te vermenigvuldigen met zijn eigen omvang gemeten in SO. Het areaal met beregening wordt bepaald door het aandeel van het areaal met beregening in het totale areaal van de bedrijven uit het Informatienet te berekenen. Vervolgens wordt het aandeel van het gematchte bedrijf vermenigvuldigd met het areaal van het landbouwtellingsbedrijf. Het beregende areaal wordt bepaald door het aantal keren dat er beregend is te berekenen op de bedrijven uit het Informatienet. Verondersteld is dat het landbouwtellingsbedrijf hetzelfde aantal keren beregent als het gematchte bedrijf. Ten slotte worden de resultaten van de landbouwtellingsbedrijven per stroomgebied geaggregeerd om tot totalen te komen voor de stroomgebieden. 


\section{$2.4 \quad$ Bijschatting}

Als het watergebruik van de steekproefpopulatie is bepaald, wordt er nog een bijschatting gemaakt. Een deel van de populatie wordt niet door de steekproef gerepresenteerd, omdat de steekproef een ondergrens kent van (25.000 euro SO). Dit deel wordt bijgeschat op basis van het gemiddelde watergebruik per SO per bedrijfstype per stroomgebied.

\subsection{Drenking vee}

Het water dat gebruikt wordt voor de drenking van het vee wordt geschat op basis van normen van het watergebruik per dier (KWIN 2009). Daarnaast worden de volgende uitgangspunten gehanteerd. Voor rundveedrenking is grondwater veel belangrijker dan oppervlaktewater, vanwege de min of meer constante waterkwaliteit. Alleen voor de diergroep rundvee wordt oppervlakte- en grondwater gebruikt naast de drenking met leidingwater. Er kan alleen oppervlakte-/grondwater worden gebruikt voor drenking als er of een boorput, of een hydrofoor of een veevelddrinkwaterinstallatie op het bedrijf aanwezig is.

Het vee kan in de praktijk ook rechtstreeks uit het oppervlaktewater drinken zonder dat bovenstaande installaties aanwezig zijn. Of dit inderdaad het geval is, is niet bekend en wordt daarom niet meegenomen in de berekening. Dit geeft mogelijk een onderschatting van de gebruikte hoeveelheid oppervlaktewater c.q. een overschatting van de hoeveelheid leidingwater gebruikt voor drenking.

Indien op een bedrijf naast rundvee ook andere dieren worden gehouden, dan wordt voor drenking van de overige dieren een normatieve hoeveelheid leidingwater berekend. Deze berekende hoeveelheid leidingwater wordt in mindering gebracht op de totaal gebruikte hoeveelheid leidingwater. Dit totale leidingwatergebruik wordt geregistreerd op basis van de afrekening van het waterbedrijf en gecorrigeerd voor huishoudelijk gebruik. Resteert er dan nog leidingwater, dan is verondersteld dat het rundvee dit voor drenking heeft gebruikt. Deze hoeveelheid water wordt in mindering gebracht op de berekende hoeveelheid voor drenking gebruikt oppervlakte- en grondwater, zoals bepaald in de vorige stap.

Voor het schoonmaken van de stallen (KWIN, 2009) en voor het gebruik van de melkrobot (Veehouderijtechniek, 2007) wordt normatief een gebruik aan leidingwater ingerekend. 


\section{Uitkomsten}

\section{$3.1 \quad$ Inleiding}

In dit hoofdstuk worden de resultaten van de berekeningen weergegeven. De resultaten worden kort geduid, maar niet uitgebreid toegelicht.

\subsection{Watergebruik land- en tuinbouw}

\subsubsection{Totaal watergebruik}

Tabel 3.1 toont het watergebruik in de agrarische sector in 2015 en 2016 (een overzicht van de diverse jaren is weergegeven in bijlage 1 , een uitsplitsing naar sector en stroomgebied is te vinden in bijlage 2). Het totale gebruik bedroeg respectievelijk ruim 148 en 120 miljoen m³. In 2015 is veel beregend zoals blijkt uit de arealen beregend en het watergebruik voor irrigatie. Vooral de maanden mei, juni en juli waren droger dan in 2016 (KNMI maandsom neerslag).

Tabel 3.1 Watergebruik $\left(1.000 \mathrm{~m}^{3}\right)$ in 2015 en 2016

\begin{tabular}{lrr} 
& 2015 & 2016 \\
Leidingwater & 42.552 & 43.477 \\
\hline w.v. drenking vee & 24.397 & 25.226 \\
\hline w.v. overig & 18.155 & 18.251 \\
\hline Gietwater & 609 & 744 \\
\hline Grondwater (irrigatie) & 49.307 & 27.604 \\
\hline Oppervlaktewater (irrigatie) & 19.046 & 9.703 \\
\hline Oppervlakte- of grondwater (drenking) & 36.938 & 38.441 \\
\hline Totaal & 148.453 & 119.970 \\
\hline
\end{tabular}

Bron: Bedrijveninformatienet en CBS Landbouwtelling, berekeningen Wageningen Economic Research.

In tabel 3.2 is weergegeven welk deel van het watergebruik is bijgeschat (zie 2.4) voor bedrijven die buiten het steekproefkader van Wageningen Economic Research vallen. Voor 2015 is de bijschatting hoger dan in 2016. In 2015 was vooral bij de akkerbouwbedrijven de bijschatting hoger. Dit kwam omdat het totale aantal SO van akkerbouwbedrijven kleiner dan 25.000 euro SO tussen 2015 en 2016 met een kwart afnam (zie ook CBS Statline).

Tabel 3.2 Bijschatting watergebruik 2015 en $2016(\%)$

\begin{tabular}{|c|c|c|}
\hline & 2015 & 2016 \\
\hline Leidingwater drenking vee & 3,3 & 2,6 \\
\hline Grondwater (irrigatie) & 4,8 & 2,6 \\
\hline Oppervlaktewater (irrigatie) & 2,0 & 1,8 \\
\hline Totaal & 3,2 & 2,0 \\
\hline
\end{tabular}

Bron: Bedrijveninformatienet en CBS Landbouwtelling, berekeningen Wageningen Economic Research. 


\subsubsection{Watergebruik per bedrijf}

In tabel 3.3 wordt het totale jaarlijkse gemiddelde watergebruik per bedrijf weergegeven. In 2015 werd er gemiddeld $2.300 \mathrm{~m}^{3}$ water per bedrijf gebruikt, waarvan bijna $700 \mathrm{~m}^{3}$ leidingwater. In 2016 was het totale watergebruik lager, maar het leidingwatergebruik nam toe (in bijlage 3 is een uitsplitsing per bedrijfstype weergegeven). De toename wordt mede veroorzaakt doordat de bedrijven steeds groter worden. Daarnaast neemt bijvoorbeeld in de fruitteelt het watergebruik toe voor het sorteren het fruit.

Tabel 3.3 Gemiddeld watergebruik $\left(m^{3}\right)$ per bedrijf, naar stroomgebied, 2015 en 2016

\begin{tabular}{|c|c|c|c|}
\hline Stroomgebied & Water & 2015 & 2016 \\
\hline \multirow[t]{2}{*}{ Eems } & Gemiddeld totaal water & 2.173 & 1.806 \\
\hline & w.v. leidingwater & 506 & 697 \\
\hline Rijn - Noord & w.v. leidingwater & 914 & 1.165 \\
\hline Rijn - Oost & Gemiddeld totaal water & 1.865 & 1.662 \\
\hline Rijn - Midden & w.v. leidingwater & 505 & 561 \\
\hline \multirow[t]{2}{*}{ Rijn - West } & Gemiddeld totaal water & 1.516 & 1.595 \\
\hline & w.v. leidingwater & 615 & 692 \\
\hline Schelde & Gemiddeld totaal water & 2.463 & 1.969 \\
\hline \multirow[t]{2}{*}{ Totaal } & Gemiddeld totaal water & 2.323 & 2.155 \\
\hline & w.v. leidingwater & 666 & 781 \\
\hline
\end{tabular}

Bron: Bedrijveninformatienet en CBS Landbouwtelling, berekeningen Wageningen Economic Research.

\subsection{Beregend areaal}

Tabel 3.4 toont het beregende areaal en het areaal met beregening. In 2015 werd er als gevolg van een droge periode meer beregend dan in 2016, respectievelijk 283.000 en 162.000 ha. Vaak worden bepaalde percelen vaker dan 1 keer beregend. Vooral in de tuinbouw wordt er veelvuldig beregend. Het areaal waarop beregening is toegepast ligt daarom lager.

Tabel 3.4 Beregend areaal (ha) naar stroomgebied, 2015 en 2016

\begin{tabular}{llrr} 
Stroomgebied & Beregening & 2015 & 2016 \\
\hline & Areaal minimaal 1 keer beregend & 7.051 & 2.702 \\
\hline & Beregend areaal & 12.977 & 4.362 \\
\hline Rijn - Noord & Areaal minimaal 1 keer beregend & 4.403 & 2.291 \\
\hline & Beregend areaal & 7.465 & 3.180 \\
\hline Rijn - Oost & Areaal minimaal 1 keer beregend & 20.164 & 6.884 \\
\hline & Beregend areaal & 36.420 & 12.697 \\
\hline Rijn - Midden & Areaal minimaal 1 keer beregend & 19.927 & 10.451 \\
\hline Rijn - West & Beregend areaal & 37.965 & 15.710 \\
\hline & Areaal minimaal 1 keer beregend & 17.104 & 10.257 \\
\hline Schelde & Beregend areaal & 36.575 & 24.868 \\
\hline & Areaal minimaal 1 keer beregend & 13.503 & 7.938 \\
\hline Maas & Beregend areaal & 26.993 & 17.173 \\
\hline Totaal & Areaal minimaal 1 keer beregend & 52.110 & 34.980 \\
\hline & Beregend areaal & 124.780 & 84.128 \\
\hline
\end{tabular}

Bron: Bedrijveninformatienet en CBS Landbouwtelling, berekeningen Wageningen Economic Research. 


\subsection{Resultaten in het kort}

- In 2015 is er aanzienlijk meer beregend dan in 2016 als gevolg van een droge periode van april tot en met juni, hierdoor is het watergebruik in 2015148 miljoen $\mathrm{m}^{3}$. In 2016 daalde dit tot 120 miljoen $\mathrm{m}^{3}$.

- Het leidingwatergebruik per bedrijf stijgt, mede door de toegenomen omvang van de bedrijven. In 2016 werd er gemiddeld bijna $800 \mathrm{~m}^{3}$ leidingwater gebruikt.

- Water voor het drenken van vee en beregening maken een groot deel uit van het totale watergebruik. 


\section{Literatuur en websites}

Ge, L., R.W. van der Meer, H.B. van der Veen H.J.C. Vrolijk, 2015. Sample of the Dutch FADN 2015. Design principles and quality of the sample of agricultural and horticultural holdings. Wageningen Economic Research report 2018-011. The Hague: Wageningen Economic Research

Slingerland, R., 2007. Lely Astronaut A3: Robot met 'brains and feelings'. In: Veehouderij techniek, november.

Meer, van der, R.W., 2014. Watergebruik in de agrarische sector 2012. LEI-nota 14-069

Meer, van der, R.W., 2016. Watergebruik in de agrarische sector 2013 en 2014. LEI-nota 2016-081

Vrolijk, H.C.J., W. Dol en T. Kuhlman, 2005. Integration of small area estimation and mapping techniques - Tool for regional studies. LEI report 8.05.01.The Hague: LEI.

Wageningen UR Livestock Research, 2009. Kwantitatieve Informatie Veehouderij (KWIN) 2009 - 2010. Lelystad: Wageningen UR Livestock Research. 


\section{Bijlage 1 Watergebruik vanaf 2001}

Tabel 1 Watergebruik (in $\mathrm{m} / \mathrm{n} . \mathrm{m}^{3}$ ), 2001-2016

\begin{tabular}{|c|c|c|c|c|c|c|c|}
\hline & $\begin{array}{l}\text { Leiding } \\
\text { water }\end{array}$ & Gietwater & $\begin{array}{l}\text { Grondwater } \\
\text { (irrigatie) }\end{array}$ & $\begin{array}{l}\text { Oppervlakte- } \\
\text { of grondwater } \\
\text { (irrigatie) }\end{array}$ & $\begin{array}{l}\text { Oppervlaktewater } \\
\text { (irrigatie) }\end{array}$ & $\begin{array}{l}\text { Oppervlakte- of } \\
\text { grondwater } \\
\text { (drenking) }\end{array}$ & Totaal \\
\hline 2002 & 50 & 3 & 23 & 8 & 12 & 38 & 134 \\
\hline 2003 & 57 & 6 & 101 & 22 & 32 & 38 & 256 \\
\hline 2005 & 47 & 3 & 24 & 6 & 6 & 36 & 122 \\
\hline 2006 & 46 & 1 & 62 & 12 & 15 & 32 & 168 \\
\hline 2007 & 46 & 3 & 19 & 9 & 9 & 33 & 118 \\
\hline 2008 & 44 & 2 & 19 & 8 & 8 & 36 & 116 \\
\hline 2012 & 39 & 1 & 18 & 1 & 3 & 37 & 99 \\
\hline 2013 & 41 & 1 & 53 & - & 13 & 39 & 148 \\
\hline 2014 & 42 & 1 & 30 & - & 10 & 41 & 125 \\
\hline 2015 & 43 & 1 & 49 & - & 19 & 37 & 148 \\
\hline 2016 & 43 & 1 & 28 & - & 10 & 38 & 120 \\
\hline
\end{tabular}

Bron: Watergebruik in de agrarische sector (diverse edities) 


\section{Bijlage 2 Watergebruik naar sector en stroomgebied}

Tabellen $2 \mathrm{a}$ en $2 \mathrm{~b}$ laten het totale geschatte watergebruik per stroomgebied en sector zien in 2015 en 2016.

Tabel 2a Watergebruik $\left(1.000 \mathrm{~m}^{3}\right)$ naar sector en stroomgebied, 2015

\begin{tabular}{|c|c|c|c|c|c|c|c|}
\hline $\begin{array}{l}\text { Stroom- } \\
\text { gebied }\end{array}$ & Watergebruik & $\begin{array}{l}\text { Akker- } \\
\text { bouw }\end{array}$ & $\begin{array}{l}\text { Tuin- } \\
\text { bouw }\end{array}$ & Fruit & $\begin{array}{r}\text { Vee- } \\
\text { houderij }\end{array}$ & $\begin{array}{r}\text { Overig } \\
\text { landbouw }\end{array}$ & Totaal \\
\hline \multirow[t]{8}{*}{ Eems } & Leidingwater & 52 & 13 & 1 & 1.075 & 74 & 1.216 \\
\hline & w.v. drenking vee & 5 & 0 & 0 & 822 & 48 & 876 \\
\hline & w.v. overig & 47 & 13 & 1 & 253 & 26 & 340 \\
\hline & Gietwater & 0 & 1 & 0 & 0 & 0 & 1 \\
\hline & Grondwater (irrigatie) & 452 & 95 & 0 & 241 & 155 & 944 \\
\hline & Oppervlaktewater (irrigatie) & 799 & 15 & 0 & 152 & 241 & 1.207 \\
\hline & Oppervlakte- of grondwater (drenking) & 0 & 0 & 0 & 1.820 & 30 & 1.849 \\
\hline & Totaal water & 1.303 & 124 & 1 & 3.289 & 500 & 5.217 \\
\hline \multirow[t]{8}{*}{ Rijn - Noord } & Leidingwater & 88 & 39 & 0 & 5.601 & 45 & 5.774 \\
\hline & w.v. drenking vee & 8 & 0 & 0 & 4.671 & 30 & 4.709 \\
\hline & w.v. overig & 80 & 39 & 0 & 930 & 15 & 1.065 \\
\hline & Gietwater & 0 & 0 & 0 & 0 & 0 & 0 \\
\hline & Grondwater (irrigatie) & 335 & 28 & 0 & 407 & 130 & 900 \\
\hline & Oppervlaktewater (irrigatie) & 199 & 16 & 0 & 158 & 126 & 499 \\
\hline & Oppervlakte- of grondwater (drenking) & 0 & 0 & 0 & 6.523 & 25 & 6.547 \\
\hline & Totaal water & 622 & 83 & 0 & 12.689 & 326 & 13.720 \\
\hline \multirow[t]{8}{*}{ Rijn - Oost } & Leidingwater & 71 & 190 & 5 & 7.406 & 193 & 7.865 \\
\hline & w.v. drenking vee & 5 & 3 & 0 & 4.572 & 109 & 4.689 \\
\hline & w.v. overig & 66 & 187 & 5 & 2.834 & 84 & 3.176 \\
\hline & Gietwater & 0 & 73 & 0 & 0 & 0 & 73 \\
\hline & Grondwater (irrigatie) & 989 & 721 & 0 & 2.828 & 613 & 5.151 \\
\hline & Oppervlaktewater (irrigatie) & 387 & 146 & 0 & 1.765 & 469 & 2.766 \\
\hline & Oppervlakte- of grondwater (drenking) & 0 & 10 & 0 & 11.087 & 71 & 11.168 \\
\hline & Totaal water & 1.447 & 1.139 & 6 & 23.086 & 1.346 & 27.024 \\
\hline \multirow[t]{8}{*}{ Rijn - Midden } & Leidingwater & 241 & 122 & 15 & 2.607 & 104 & 3.090 \\
\hline & w.v. drenking vee & 17 & 1 & 0 & 1.692 & 58 & 1.767 \\
\hline & w.v. overig & 224 & 121 & 15 & 915 & 46 & 1.323 \\
\hline & Gietwater & 0 & 19 & 1 & 0 & 0 & 20 \\
\hline & Grondwater (irrigatie) & 2.812 & 264 & 1 & 1.412 & 223 & 4.712 \\
\hline & Oppervlaktewater (irrigatie) & 1.137 & 85 & 0 & 1.326 & 539 & 3.088 \\
\hline & $\begin{array}{l}\text { Oppervlakte- of grondwater } \\
\text { (drenking) }\end{array}$ & 0 & 0 & 0 & 3.356 & 79 & 3.436 \\
\hline & Totaal water & 4.191 & 491 & 16 & 8.700 & 947 & 14.345 \\
\hline \multirow[t]{8}{*}{ Rijn - West } & Leidingwater & 198 & 1.541 & 148 & 7.539 & 86 & 9.513 \\
\hline & w.v. drenking vee & 3 & 19 & 0 & 5.969 & 49 & 6.040 \\
\hline & w.v. overig & 195 & 1.522 & 148 & 1.570 & 37 & 3.473 \\
\hline & Gietwater & 0 & 92 & 30 & 0 & 0 & 122 \\
\hline & Grondwater (irrigatie) & 1.093 & 1.253 & 0 & 1.386 & 187 & 3.920 \\
\hline & Oppervlaktewater (irrigatie) & 1.656 & 374 & 0 & 1.057 & 248 & 3.335 \\
\hline & $\begin{array}{l}\text { Oppervlakte- of grondwater } \\
\text { (drenking) }\end{array}$ & 1 & 2 & 0 & 6.479 & 71 & 6.553 \\
\hline & Totaal water & 2.949 & 3.262 & 178 & 16.461 & 593 & 23.443 \\
\hline
\end{tabular}




\begin{tabular}{|c|c|c|c|c|c|c|c|}
\hline $\begin{array}{l}\text { Stroom- } \\
\text { gebied }\end{array}$ & Watergebruik & $\begin{array}{l}\text { Akker- } \\
\text { bouw }\end{array}$ & $\begin{array}{l}\text { Tuin- } \\
\text { bouw }\end{array}$ & Fruit & $\begin{array}{r}\text { Vee- } \\
\text { houderij }\end{array}$ & $\begin{array}{r}\text { Overig } \\
\text { landbouw }\end{array}$ & Totaal \\
\hline \multirow[t]{8}{*}{ Schelde } & Leidingwater & 283 & 61 & 429 & 579 & 29 & 1.382 \\
\hline & w.v. drenking vee & 4 & 2 & 0 & 416 & 22 & 444 \\
\hline & w.v. overig & 279 & 59 & 429 & 163 & 7 & 938 \\
\hline & Gietwater & 0 & 4 & 304 & 0 & 0 & 308 \\
\hline & Grondwater (irrigatie) & 997 & 376 & 0 & 1.173 & 323 & 2.869 \\
\hline & Oppervlaktewater (irrigatie) & 2.498 & 58 & 0 & 309 & 156 & 3.021 \\
\hline & $\begin{array}{l}\text { Oppervlakte- of grondwater } \\
\text { (drenking) }\end{array}$ & 0 & 0 & 0 & 553 & 30 & 583 \\
\hline & Totaal water & 3.779 & 500 & 733 & 2.614 & 539 & 8.164 \\
\hline \multirow[t]{8}{*}{ Maas } & Leidingwater & 279 & 859 & 106 & 12.094 & 375 & 13.713 \\
\hline & w.v. drenking vee & 4 & 22 & 0 & 5.617 & 229 & 5.872 \\
\hline & w.v. overig & 275 & 837 & 106 & 6.477 & 146 & 7.841 \\
\hline & Gietwater & 0 & 51 & 34 & 0 & 0 & 85 \\
\hline & Grondwater (irrigatie) & 3.905 & 7.346 & 10 & 16.552 & 2.998 & 30.810 \\
\hline & Oppervlaktewater (irrigatie) & 2.038 & 409 & 0 & 1.783 & 899 & 5.130 \\
\hline & $\begin{array}{l}\text { Oppervlakte- of grondwater } \\
\text { (drenking) }\end{array}$ & 2 & 0 & 0 & 6.484 & 316 & 6.802 \\
\hline & Totaal water & 6.223 & 8.665 & 150 & 36.913 & 4.588 & 56.540 \\
\hline \multirow[t]{8}{*}{ Totaal } & Leidingwater & 1.212 & 2.826 & 705 & 36.901 & 908 & 42.552 \\
\hline & w.v. drenking vee & 46 & 47 & 0 & 23.759 & 544 & 24.397 \\
\hline & w.v. overig & 1.166 & 2.779 & 705 & 13.142 & 364 & 18.155 \\
\hline & Gietwater & 0 & 241 & 368 & 0 & 0 & 609 \\
\hline & Grondwater (irrigatie) & 10.584 & 10.083 & 11 & 24.000 & 4.629 & 49.307 \\
\hline & Oppervlaktewater (irrigatie) & 8.715 & 1.103 & 0 & 6.549 & 2.679 & 19.046 \\
\hline & $\begin{array}{l}\text { Oppervlakte- of grondwater } \\
\text { (drenking) }\end{array}$ & 4 & 12 & 0 & 36.301 & 622 & 36.938 \\
\hline & Totaal water & 20.514 & 14.265 & 1.085 & 103.752 & 8.838 & 148.453 \\
\hline
\end{tabular}

Bron: Bedrijveninformatienet en CBS Landbouwtelling. berekeningen Wageningen Economic Research.

Tabel $2 b$

Watergebruik $\left(1.000 \mathrm{~m}^{3}\right)$ naar sector en stroomgebied, 2016

\begin{tabular}{|c|c|c|c|c|c|c|c|}
\hline $\begin{array}{l}\text { Stroom- } \\
\text { gebied }\end{array}$ & Watergebruik & $\begin{array}{l}\text { Akker- } \\
\text { bouw }\end{array}$ & $\begin{array}{l}\text { Tuin- } \\
\text { bouw }\end{array}$ & Fruit & $\begin{array}{r}\text { Vee- } \\
\text { houderij }\end{array}$ & $\begin{array}{r}\text { Overig } \\
\text { landbouw }\end{array}$ & Totaal \\
\hline \multirow[t]{8}{*}{ Eems } & Leidingwater & 60 & 14 & 1 & 1.263 & 156 & 1.492 \\
\hline & w.v. drenking vee & 3 & 0 & 0 & 976 & 95 & 1.074 \\
\hline & w.v. overig & 57 & 14 & 1 & 287 & 61 & 418 \\
\hline & Gietwater & 0 & 0 & 0 & 0 & 0 & 0 \\
\hline & Grondwater (irrigatie) & 169 & 121 & 0 & 15 & 43 & 348 \\
\hline & Oppervlaktewater (irrigatie) & 175 & 6 & 0 & 8 & 38 & 228 \\
\hline & $\begin{array}{l}\text { Oppervlakte- of grondwater } \\
\text { (drenking) }\end{array}$ & 0 & 0 & 0 & 1.773 & 26 & 1.799 \\
\hline & Totaal water & 403 & 141 & 1 & 3.059 & 263 & 3.866 \\
\hline \multirow[t]{8}{*}{ Rijn - Noord } & Leidingwater & 114 & 48 & 1 & 6.447 & 93 & 6.703 \\
\hline & w.v. drenking vee & 6 & 0 & 0 & 5.361 & 58 & 5.425 \\
\hline & w.v. overig & 108 & 48 & 1 & 1.086 & 35 & 1.278 \\
\hline & Gietwater & 0 & 1 & 0 & 0 & 0 & 1 \\
\hline & Grondwater (irrigatie) & 222 & 38 & 0 & 36 & 18 & 313 \\
\hline & Oppervlaktewater (irrigatie) & 213 & 5 & 1 & 25 & 22 & 266 \\
\hline & $\begin{array}{l}\text { Oppervlakte- of grondwater } \\
\text { (drenking) }\end{array}$ & 0 & 0 & 0 & 7.880 & 22 & 7.902 \\
\hline & Totaal water & 549 & 92 & 2 & 14.388 & 155 & 15.186 \\
\hline \multirow[t]{6}{*}{ Rijn - Oost } & Leidingwater & 63 & 227 & 6 & 7.488 & 183 & 7.968 \\
\hline & w.v. drenking vee & 4 & 2 & 0 & 4.948 & 110 & 5.064 \\
\hline & w.v. overig & 59 & 225 & 6 & 2.540 & 73 & 2.904 \\
\hline & Gietwater & 0 & 105 & 1 & 0 & 0 & 106 \\
\hline & Grondwater (irrigatie) & 749 & 503 & 0 & 399 & 235 & 1.886 \\
\hline & Oppervlaktewater (irrigatie) & 272 & 48 & 20 & 68 & 42 & 450 \\
\hline
\end{tabular}




\begin{tabular}{|c|c|c|c|c|c|c|c|}
\hline \multirow[t]{3}{*}{$\begin{array}{l}\text { Stroom- } \\
\text { gebied }\end{array}$} & Watergebruik & $\begin{array}{l}\text { Akker- } \\
\text { bouw }\end{array}$ & $\begin{array}{l}\text { Tuin- } \\
\text { bouw }\end{array}$ & Fruit & $\begin{array}{r}\text { Vee- } \\
\text { houderij }\end{array}$ & $\begin{array}{r}\text { Overig } \\
\text { landbouw }\end{array}$ & Totaal \\
\hline & $\begin{array}{l}\text { Oppervlakte- of grondwater } \\
\text { (drenking) }\end{array}$ & 0 & 10 & 0 & 10.630 & 51 & 10.690 \\
\hline & Totaal water & 1.084 & 893 & 26 & 18.584 & 511 & 21.100 \\
\hline \multirow[t]{8}{*}{ Rijn - Midden } & Leidingwater & 205 & 122 & 27 & 2.499 & 128 & 2.982 \\
\hline & w.v. drenking vee & 8 & 0 & 0 & 1.626 & 81 & 1.715 \\
\hline & w.v. overig & 197 & 122 & 27 & 873 & 47 & 1.267 \\
\hline & Gietwater & 0 & 16 & 10 & 0 & 0 & 26 \\
\hline & Grondwater (irrigatie) & 751 & 329 & 0 & 441 & 177 & 1.699 \\
\hline & Oppervlaktewater (irrigatie) & 956 & 26 & 0 & 123 & 58 & 1.164 \\
\hline & $\begin{array}{l}\text { Oppervlakte- of grondwater } \\
\text { (drenking) }\end{array}$ & 0 & 2 & 0 & 3.568 & 90 & 3.660 \\
\hline & Totaal water & 1.913 & 496 & 37 & 6.632 & 454 & 9.531 \\
\hline \multirow[t]{8}{*}{ Rijn - West } & Leidingwater & 170 & 1.556 & 184 & 6.848 & 68 & 8.826 \\
\hline & w.v. drenking vee & 2 & 22 & 0 & 5.291 & 39 & 5.353 \\
\hline & w.v. overig & 168 & 1.534 & 184 & 1.557 & 29 & 3.473 \\
\hline & Gietwater & 0 & 25 & 28 & 0 & 0 & 53 \\
\hline & Grondwater (irrigatie) & 655 & 1.858 & 0 & 498 & 145 & 3.156 \\
\hline & Oppervlaktewater (irrigatie) & 1.547 & 165 & 3 & 60 & 5 & 1.779 \\
\hline & $\begin{array}{l}\text { Oppervlakte- of grondwater } \\
\text { (drenking) }\end{array}$ & 0 & 5 & 0 & 6.475 & 67 & 6.547 \\
\hline & Totaal water & 2.372 & 3.608 & 215 & 13.881 & 285 & 20.362 \\
\hline \multirow[t]{8}{*}{ Schelde } & Leidingwater & 236 & 79 & 636 & 685 & 58 & 1.694 \\
\hline & w.v. drenking vee & 1 & 6 & 0 & 498 & 31 & 536 \\
\hline & w.v. overig & 235 & 73 & 636 & 187 & 27 & 1.158 \\
\hline & Gietwater & 0 & 0 & 454 & 0 & 0 & 454 \\
\hline & Grondwater (irrigatie) & 395 & 414 & 0 & 314 & 203 & 1.325 \\
\hline & Oppervlaktewater (irrigatie) & 1.912 & 56 & 0 & 11 & 21 & 1.999 \\
\hline & $\begin{array}{l}\text { Oppervlakte- of grondwater } \\
\text { (drenking) }\end{array}$ & 0 & 0 & 0 & 529 & 33 & 562 \\
\hline & Totaal water & 2.543 & 548 & 1.090 & 1.538 & 315 & 6.034 \\
\hline \multirow[t]{8}{*}{ Maas } & Leidingwater & 240 & 968 & 121 & 12.206 & 276 & 13.811 \\
\hline & w.v. drenking vee & 4 & 29 & 0 & 5.889 & 138 & 6.060 \\
\hline & w.v. overig & 236 & 939 & 121 & 6.317 & 138 & 7.751 \\
\hline & Gietwater & 0 & 63 & 41 & 0 & 0 & 104 \\
\hline & Grondwater (irrigatie) & 3.679 & 7.701 & 0 & 5.627 & 1.870 & 18.877 \\
\hline & Oppervlaktewater (irrigatie) & 1.716 & 1.781 & 93 & 101 & 126 & 3.818 \\
\hline & $\begin{array}{l}\text { Oppervlakte- of grondwater } \\
\text { (drenking) }\end{array}$ & 0 & 0 & 0 & 6.979 & 303 & 7.282 \\
\hline & Totaal water & 5.634 & 10.513 & 255 & 24.913 & 2.576 & 43.891 \\
\hline \multirow[t]{8}{*}{ Totaal } & Leidingwater & 1.089 & 3.014 & 974 & 37.436 & 963 & 43.477 \\
\hline & w.v. drenking vee & 27 & 58 & 0 & 24.590 & 552 & 25.226 \\
\hline & w.v. overig & 1.062 & 2.956 & 974 & 12.846 & 411 & 18.251 \\
\hline & Gietwater & 0 & 210 & 534 & 0 & 0 & 744 \\
\hline & Grondwater (irrigatie) & 6.619 & 10.963 & 0 & 7.331 & 2.691 & 27.604 \\
\hline & Oppervlaktewater (irrigatie) & 6.791 & 2.087 & 117 & 396 & 313 & 9.703 \\
\hline & $\begin{array}{l}\text { Oppervlakte- of grondwater } \\
\text { (drenking) }\end{array}$ & 0 & 17 & 0 & 37.832 & 592 & 38.441 \\
\hline & Totaal water & 14.499 & 16.291 & 1.625 & 82.996 & 4.559 & 119.970 \\
\hline
\end{tabular}

Bron: Bedrijveninformatienet en CBS Landbouwtelling. berekeningen Wageningen Economic Research. 


\section{Bijlage 3 Watergebruik per bedrijf}

Onderstaande tabellen tonen het watergebruik per bedrijf naar type en stroomgebied in respectievelijk 2015 en 2016.

Tabel 3a Gemiddeld watergebruik $\left(m^{3}\right)$ per bedrijf naar stroomgebied en bedrijfstype, 2015

\begin{tabular}{|c|c|c|c|c|c|c|c|}
\hline $\begin{array}{l}\text { Stroom- } \\
\text { gebied }\end{array}$ & Water & $\begin{array}{l}\text { Akker- } \\
\text { bouw }\end{array}$ & $\begin{array}{l}\text { Tuin- } \\
\text { bouw }\end{array}$ & Fruit & $\begin{array}{r}\text { Vee- } \\
\text { houderij }\end{array}$ & $\begin{array}{l}\text { Overig } \\
\text { landbouw }\end{array}$ & Totaal \\
\hline \multirow[t]{2}{*}{ Eems } & Gemiddeld totaal water & 1.247 & 1.518 & 143 & 2.780 & 5.949 & 2.173 \\
\hline & w.v. leidingwater & 50 & 164 & 143 & 909 & 882 & 506 \\
\hline \multirow[t]{2}{*}{ Rijn - Noord } & Gemiddeld totaal water & 760 & 770 & 35 & 2.386 & 5.253 & 2.172 \\
\hline & w.v. leidingwater & 108 & 362 & 35 & 1.053 & 733 & 914 \\
\hline \multirow[t]{2}{*}{ Rijn - Oost } & Gemiddeld totaal water & 663 & 2.310 & 147 & 2.004 & 5.258 & 1.865 \\
\hline & w.v. leidingwater & 32 & 385 & 134 & 643 & 754 & 543 \\
\hline \multirow[t]{2}{*}{ Rijn - Midden } & Gemiddeld totaal water & 3.184 & 1.611 & 215 & 2.022 & 7.760 & 2.343 \\
\hline & w.v. leidingwater & 183 & 401 & 200 & 606 & 856 & 505 \\
\hline \multirow[t]{2}{*}{ Rijn - West } & Gemiddeld totaal water & 1.748 & 830 & 227 & 1.925 & 1.165 & 1.516 \\
\hline & w.v. leidingwater & 117 & 392 & 189 & 882 & 170 & 615 \\
\hline \multirow[t]{2}{*}{ Schelde } & Gemiddeld totaal water & 1.933 & 2.449 & 2.608 & 3.566 & 3.820 & 2.463 \\
\hline & w.v. leidingwater & 145 & 300 & 1.526 & 790 & 208 & 417 \\
\hline \multirow[t]{2}{*}{ Maas } & Gemiddeld totaal water & 1.824 & 3.247 & 515 & 4.202 & 7.048 & 3.577 \\
\hline & w.v. leidingwater & 82 & 322 & 364 & 1.377 & 576 & 868 \\
\hline \multirow[t]{2}{*}{ Totaal } & Gemiddeld totaal water & 1.652 & 1.830 & 728 & 2.569 & 4.843 & 2.323 \\
\hline & w.v. leidingwater & 98 & 363 & 473 & 914 & 497 & 666 \\
\hline
\end{tabular}

Tabel 3b Gemiddeld watergebruik (m3) per bedrijf naar stroomgebied en bedrijfstype, 2016

\begin{tabular}{|c|c|c|c|c|c|c|c|}
\hline $\begin{array}{l}\text { Stroom- } \\
\text { gebied }\end{array}$ & Water & $\begin{array}{l}\text { Akker- } \\
\text { bouw }\end{array}$ & $\begin{array}{l}\text { Tuin- } \\
\text { bouw }\end{array}$ & Fruit & $\begin{array}{r}\text { Vee- } \\
\text { houderij }\end{array}$ & $\begin{array}{l}\text { Overig } \\
\text { landbouw }\end{array}$ & Totaal \\
\hline \multirow[t]{2}{*}{ Eems } & Gemiddeld totaal water & 405 & 1.905 & 109 & 3.124 & 3.027 & 1.806 \\
\hline & w.v. leidingwater & 60 & 188 & 109 & 1.290 & 1.790 & 697 \\
\hline \multirow[t]{2}{*}{ Rijn - Noord } & Gemiddeld totaal water & 761 & 868 & 188 & 2.963 & 2.458 & 2.638 \\
\hline & w.v. leidingwater & 159 & 454 & 64 & 1.328 & 1.474 & 1.165 \\
\hline \multirow[t]{2}{*}{ Rijn - Oost } & Gemiddeld totaal water & 567 & 2.127 & 585 & 1.848 & 1.952 & 1.662 \\
\hline & w.v. leidingwater & 33 & 541 & 133 & 744 & 700 & 627 \\
\hline \multirow[t]{2}{*}{ Rijn - Midden } & Gemiddeld totaal water & 1.633 & 1.776 & 497 & 1.808 & 3.630 & 1.793 \\
\hline & w.v. leidingwater & 175 & 438 & 363 & 682 & 1.028 & 561 \\
\hline \multirow[t]{2}{*}{ Rijn - West } & Gemiddeld totaal water & 1.743 & 999 & 296 & 2.110 & 586 & 1.595 \\
\hline & w.v. leidingwater & 125 & 431 & 254 & 1.041 & 140 & 692 \\
\hline \multirow[t]{2}{*}{ Schelde } & Gemiddeld totaal water & 1.400 & 2.648 & 4,067 & 2.388 & 2.440 & 1.969 \\
\hline & w.v. leidingwater & 130 & 382 & 2.373 & 1.064 & 450 & 553 \\
\hline \multirow[t]{2}{*}{ Maas } & Gemiddeld totaal water & 1.971 & 4.258 & 784 & 3.257 & 4.025 & 3.148 \\
\hline & w.v. leidingwater & 84 & 392 & 371 & 1.596 & 431 & 991 \\
\hline \multirow[t]{2}{*}{ Totaal } & Gemiddeld totaal water & 1.338 & 2.274 & 1.119 & 2.410 & 2.543 & 2.155 \\
\hline & w.v. leidingwater & 100 & 421 & 671 & 1.087 & 537 & 781 \\
\hline
\end{tabular}




\section{Bijlage 4 Statistical matching}

Voor het bijschatten en wegen van de kengetallen worden de steekproefgegevens op de beschikbare gegevens over de steekproefpopulatie geprojecteerd. Wageningen Economic Research heeft hiervoor een statistical matchingsprocedure ontwikkeld. Als input worden twee datasets gemaakt. In de eerste dataset staan de bedrijven binnen de steekproefpopulatie (in dit geval de bedrijven in de Landbouwtelling binnen de steekproefgrens) met de karakteristieken waarmee de matching plaats gaat vinden. In de tweede dataset staan de steekproefbedrijven met dezelfde karakteristieken. De bedrijfskarakteristieken (ook wel matchingvariabelen genoemd) vormen de basis waarmee de steekproef- en populatiebedrijven vervolgens onderling worden vergeleken en gematcht.

Bij statistical matching worden de bedrijfskarakteristieken, die zowel in de steekproef als steekproefpopulatie bekend zijn, gebruikt om voor elk bedrijf in de steekproefpopulatie een aantal 'meest gelijkende' steekproefbedrijven af te leiden. Hierbij kan onderscheid worden gemaakt tussen kenmerken die exact overeen moeten komen en kenmerken van het steekproefbedrijf die zo gelijk mogelijk moeten zijn aan het bedrijf in de steekproefpopulatie. De 'zo gelijk mogelijk' te matchen kenmerken zijn door verschillende gewichten weer te onderscheiden naar belang. Elk bedrijf uit de steekproefpopulatie wordt gematcht met een aantal bedrijven uit de steekproef. Daarbij krijgt elk van die steekproefbedrijven een gewicht, optellend tot 1 . Het best bijpassende bedrijf krijgt het hoogste gewicht.

Per steekproefpopulatiebedrijf uit de Landbouwtelling worden vervolgens de watergebruiken per SO van de best bijpassende steekproefbedrijven vermenigvuldigd met de SO van het steekproefpopulatiebedrijf en de berekende gewichten. Zo kan elk steekproefpopulatiebedrijf een individuele schatting van een bedrijfskarakteristiek krijgen (in dit geval het watergebruik).

Centrale veronderstelling bij statistical matching is dat op basis van bedrijven die wat betreft de matchingvariabelen gelijk of zo gelijk mogelijk zijn, een schatting kan worden gemaakt van de doelvariabelen (in dit geval het watergebruik). 
Wageningen Economic Research Postbus 29703

2502 LS Den Haag

T 0703358330

E communications.ssg@wur.nl

www.wur.nl/economic-research

Wageningen Economic Research NOTA

2018-105
De missie van Wageningen University \& Research is 'To explore the potential of nature to improve the quality of life'. Binnen Wageningen University \& Research bundelen Wageningen University en gespecialiseerde onderzoeksinstituten van Stichting Wageningen Research hun krachten om bij te dragen aan de oplossing van belangrijke vragen in het domein van gezonde voeding en leefomgeving. Met ongeveer 30 vestigingen, 5.000 medewerkers en 10.000 studenten behoort Wageningen University \& Research wereldwijd tot de aansprekende kennisinstellingen binnen haar domein. De integrale benadering van de vraagstukken en de samenwerking tussen verschillende disciplines vormen het hart van de unieke Wageningen aanpak.

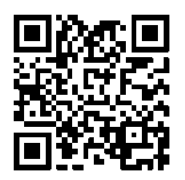





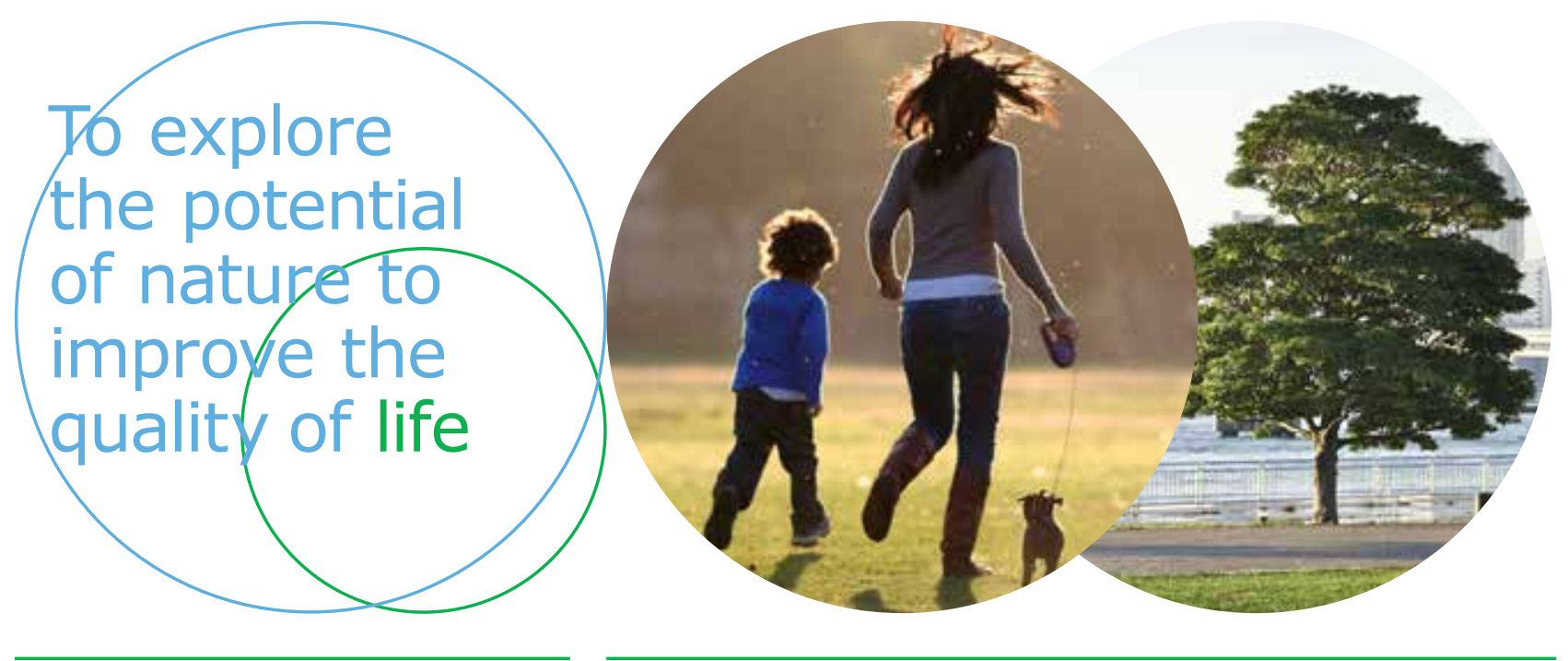

Wageningen Economic Research Postbus 29703

2502 LS Den Haag

E communications.ssg@wur.nl

T+31(0)7033583 30

www.wur.nl/economic-research

Nota 2018-105
De missie van Wageningen University \& Research is 'To explore the potential of nature to improve the quality of life'. Binnen Wageningen University \& Research bundelen Wageningen University en gespecialiseerde onderzoeksinstituten van Stichting Wageningen Research hun krachten om bij te dragen aan de oplossing van belangrijke vragen in het domein van gezonde voeding en leefomgeving. Met ongeveer 30 vestigingen, 5.000 medewerkers en 10.000 studenten behoort Wageningen University \& Research wereldwijd tot de aansprekende kennisinstellingen binnen haar domein. De integrale benadering van de vraagstukken en de samenwerking tussen verschillende disciplines vormen het hart van de unieke Wageningen aanpak. 